\title{
A Model for In-Plane Capacity of Multi-Leaf Stone Masonry Walls
}

\author{
Jagat Kumar Shrestha $(\mathbb{D})$ and Sujit Bhandari \\ Department of Civil Engineering, Pulchowk Campus, Institute of Engineering, Tribhuvan University, Kirtipur, Nepal \\ Correspondence should be addressed to Jagat Kumar Shrestha; jagatshrestha@ioe.edu.np
}

Received 1 October 2019; Accepted 13 January 2020; Published 7 February 2020

Academic Editor: Junhwan Lee

Copyright (c) 2020 Jagat Kumar Shrestha and Sujit Bhandari. This is an open access article distributed under the Creative Commons Attribution License, which permits unrestricted use, distribution, and reproduction in any medium, provided the original work is properly cited.

\begin{abstract}
Masonry walls with distinct layers, known as multi-leaf masonry walls, are prevalent in many regions of the world including ancient architecture in Europe and new construction in the Himalayan region of South Asia. This paper presents a model for determining the capacity of multi-leaf stone masonry wall from its physical and mechanical parameters. For the study, a "Standard Wall" with typical properties of a multi-leaf stone masonry wall is defined and the capacity of the stone masonry wall is studied varying different physical and mechanical parameters of the wall to explore an analytical model that can represent the capacity of multi-leaf stone masonry. 300 models of multi-leaf stone masonry panels are analysed in ANSYS, and the capacity and displacement parameters are extracted by bilinearization of the pushover curve. As a result, a mathematical model between the capacity of a multi-leaf stone masonry wall and physical and mechanical properties is established.
\end{abstract}

\section{Introduction}

Masonry structures occupy a huge stack of construction in the cities with ancient heritage and in rural areas of developing countries. In the Himalayan region of South Asia covering Nepal, India, Pakistan, and Afghanistan, stone masonry is used owing to the abundance of stones in these regions, easy construction, and good thermal insulation of thick walls of stone masonry.

Though masonry is one of the oldest constructions, it might be one of the least studied areas in terms of its capacity and its nonlinearity. One of the early works in nonlinearity of masonry was by Tomazevic [1] followed by the simplified analysis method (SAM) [2]. Then came modifications to SAM known as the equivalent frame method (EFM) [3-6]. TREMURI software provides an implementation of EFM [7]. Along with simplified EFM, finite element method (FEM) [8-10] and numerical modelling [11] have also been used for the analysis of masonry. However, most of these works are in the field of brick masonry.

The placement of stones and variation in shape, size, and strength of the stones make stone masonry vary widely compared to brick masonry. Eurocode 6 [12] classifies masonry wall by cross-section into single-leaf wall, double- leaf wall, cavity wall, and grouted cavity wall. Binda et al. [13] have similarly classified the cross-section as (a) single leaf or solid, (b) two leaves without connection, (c) two leaves with connection, and (d) three leaves from the study of monumental buildings (Figure 1). From the observation of prevalent practices in Himalayan regions, this classification is relevant to the current practice as well.

Works in the field of nonlinear analysis of stone masonry and multi-leaf stone masonry are rare compared to those of brick masonry. Finite element modelling with macromodelling and simplified micromodelling approach and numerical models have been proposed for multi-leaf stone masonry [14-18]. Experimental testing to find the mechanical properties of stone masonry have been conducted by different authors [19-21]. Tests on multi-leaf stone masonry walls have been conducted by Anzani et al. [22] and Krzan [18], whereas full-scale testing on stone masonry has been done by Mazzon et al. [23], Magenes et al. [24], and Ali et al. [25].

Approaches to find the capacity of masonry wall are mostly based on finite element modelling and are timeconsuming and, in many cases, beyond the expertise of a practicing designer or constructor. Also, it is difficult to predict the capacity of multi-leaf stone masonry walls from 


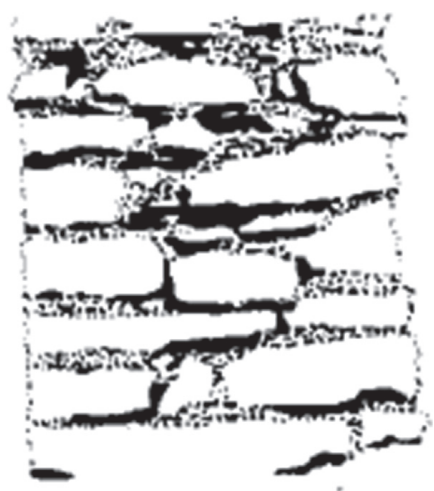

(a)

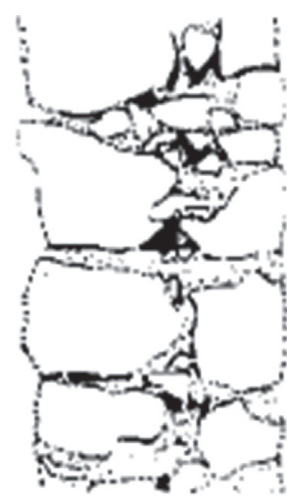

(b)

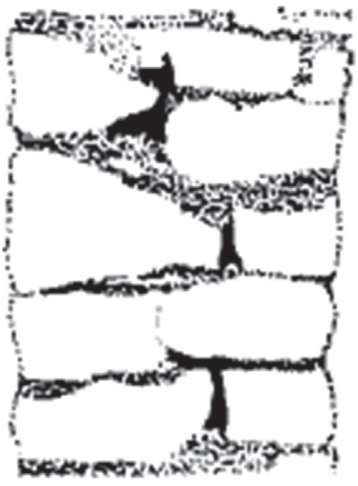

(c)

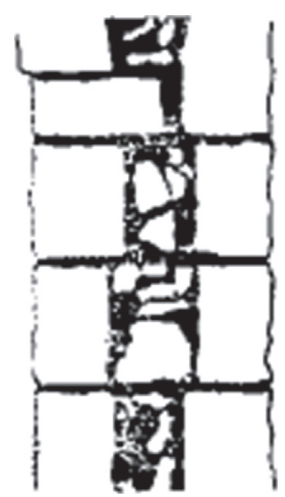

(d)

Figure 1: Stone Masonry classification by cross section: (a) single leaf or solid, (b) two leaves without connection, (c) two leaves with connection, and (d) three leaves (courtesy: [13]).

experimental works for general wall models. In this paper, an empirical relationship is formulated for the capacity assessment of multi-leaf stone masonry wall from the mechanical and physical parameters of wall that are easy to obtain.

The in-plane behaviour of masonry is looked upon, along with the modelling options. One of the modelling options for multi-leaf stone masonry is chosen using eightnoded 3D elements and Drucker-Prager Concrete model with hardening and softening functions. The model proposed is validated against an experimental wall. Once validated, a "Standard Wall" is defined with typical dimensions and properties of a multi-leaf stone masonry wall. Different parameters are then varied from that those of the typical model to see the effects of these parameters on the capacity of the wall. The results are presented in the graphical form. The dataset obtained is then turned into mathematical model via regression.

\section{Finite Element Modelling of In- Plane Behaviour}

Due to the large stiffness of a masonry wall in the in-plane direction as compared with the out-of-plane direction, during lateral loading, the capacity of a masonry structure is mainly governed by the capacity of walls in direction of loading. The focus of this study is analytical modelling, and to model the response of masonry wall subjected to in-plane loading, a finite element package ANSYS Mechanical APDL (MAPDL), a scripting software by ANSYS Inc., has been used to model the masonry and analysed to compare the result with experimental results. Among the available solids, SOLID185 defined by eight nodes and three degrees of freedom at each node is used to represent the walls with enhanced strain formulation to prevent volumetric and shear locking [26]. The contact between the leaves is modelled using planar contact elements (CONTA174 and TARGET170), defined primarily by coefficient of friction and adhesion. The Drucker-Prager concrete failure model that consists of Rankine failure surface in tension and Drucker-Prager failure surface in compression has been employed to model the nonlinearity of material of the masonry as it is well-suited for brittle material with low tensile strength compared with compressive strength [26].

For all analyses, the cantilever support condition is assumed with bottom face fixed and top face free as considered by Aldemir [27] in a similar study. The precompression pressure from top is applied on the first step and the lateral loading in the form of controlled displacement applied till failure. The vertical compressive pressure on the wall is distributed on the ratio of modulus of elasticity and thickness of the wall, as given by Binda et al. [28]. The simplified version of the formulation given by Binda et al. [28] is used for walls with equal thickness on the outer side as given in

$$
\begin{aligned}
p_{0} & =\frac{E_{o} t_{o}}{2 E_{o} t_{o}+E_{i} t_{i}} \cdot \frac{2 t_{o}+t_{i}}{t_{o}} \cdot p, \\
p_{i} & =\frac{E_{i} t_{i}}{2 E_{o} t_{o}+E_{i} t_{i}} \cdot \frac{2 t_{o}+t_{i}}{t_{i}} \cdot p,
\end{aligned}
$$

where $p$ is the initial total pressure taken as percentage of compressive strength of outer wall, $p_{o}$ and $p_{i}$ are the distributed pressure on the outer and inner leaves, respectively, $E_{o}$ and $E_{i}$ are the modulus of elasticity of the outer and inner leaves, respectively, and $t_{o}$ and $t_{i}$ are the thickness of outer and inner leaves, respectively.

The proposed model is validated based on the experimental work done by Krzan [18]. A three-leaf stone masonry wall with no connecting stones and cantilever support condition, named SNk-7.5-1, construction shown in Figure 2, is used for the validation. For the experimental set up, results, and mechanical properties, refer Krzan [18]. The contribution of plaster is not considered in determining the lateral load taking capacity of the wall. The analytical and experimental pushover curves are presented in Figure 3. The trend of analytical result matches with the experimental result closely.

The failure mechanism for the experimental wall is described as rocking failure, and the side view shown in Figure 4(a). Please note that the wall for the test was fixed at the top and lateral displacement applied at the bottom. From 


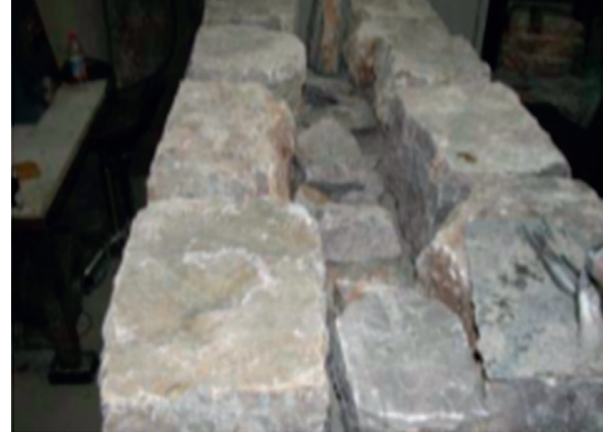

(a)

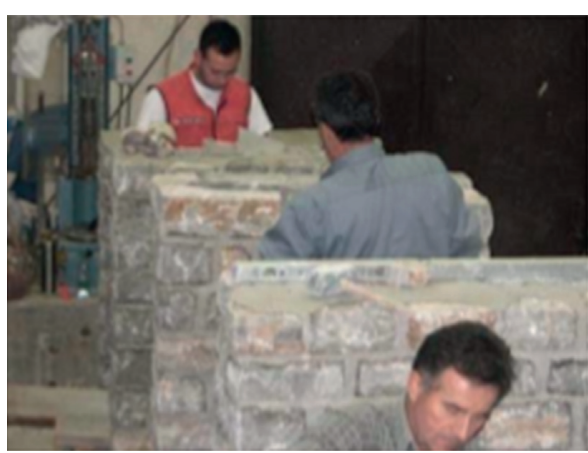

(b)

FIgURE 2: Construction of wall with no connecting stones [18].

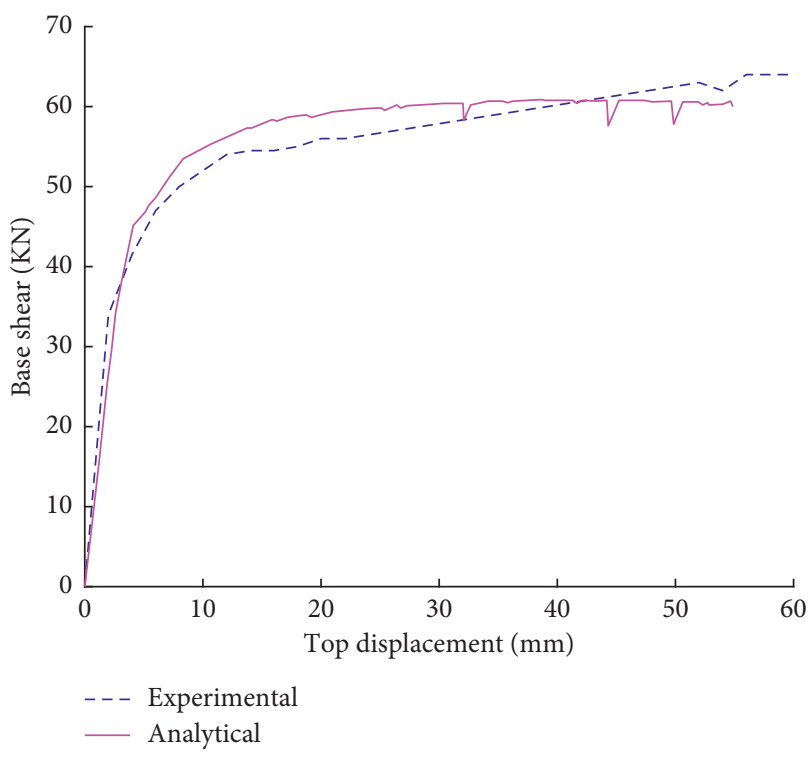

Figure 3: Pushover curve of the SNk-7.5-1 wall [18].

the strain plot in Figure 4(b), the tensile strain is maximum at the bottom of the wall, decreasing along the transverse to a low value of compressive strain showing a rocking failure mechanism.

\section{Capacity of Multi-Leaf Stone Masonry Panel}

An analytical study on the effect of different properties of a multi-leaf stone masonry panel has been made in this study. A typical panel "Standard Wall" is defined so that it represents the typical parameters of a multi-leaf stone masonry wall. This would facilitate in deriving the relationship of the capacity parameters with the physical and mechanical parameters of the wall. Before defining the typical parameters, a range of mechanical parameters of multi-leaf stone masonry is presented in Table 1, compiled from experiments or compilations in different literatures. A wide variation in properties can be seen in Table 1 owing to the variation in properties of the constituent materials, construction techniques, and workmanship.

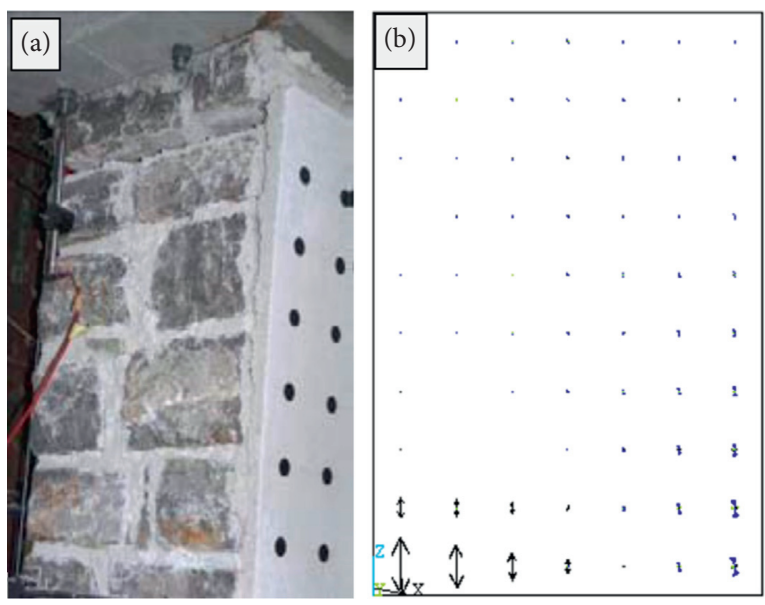

Figure 4: (a) Crack pattern on wall SNk-7.5-1, side view [18] and (b) strain plot from analysis (strain shown by arrows).

Apart from the mechanical properties in Table 1, other parameters of interest are cohesion and coefficient of friction. Values ranging from $0.5-0.58$ have been used for coefficient of friction and $0.1-0.23 \mathrm{MPa}$ for cohesion as adopted by Rizzano and Sabatino [5]. Eurocode 6 [12] implicitly proposes a value of 0.4 and $0.1 \mathrm{MPa}$ for coefficient of friction and cohesion, respectively. However, there seems to be no agreement on the determination of modulus of elasticity from compressive strength of stone masonry. Though all codes propose a linear relationship, the multiplier to obtain Young's Modulus from compressive strength is 1000, 750, and 200 as per Eurocode 6 [12], Building Code of Pakistan [32], and Turkish Code [34].

The physical dimensions of the "Standard Wall" are taken from the experiment of the panel tested by Krzan [18], length of 1 meter, height of 1.5 meter, and a total thickness of 0.4 meters. The compressive strength is taken as $3.2 \mathrm{MPa}$, in accordance with the average result from the experiment by Magenes et al. [20], tensile strength taken as $4 \%$ of the compressive strength. The vertical precompression on the wall is taken as $7.5 \%$ and distributed as per equations (1) and (2). Modulus of elasticity $(E)$ is taken in line with the mean value given by the experiment of Magenes et al. [20] and 
TABLE 1: Mechanical properties of stone masonry from experiments and codes.

\begin{tabular}{|c|c|c|c|c|}
\hline Source & $\begin{array}{l}\text { Compressive strength } \\
\left(f_{\mathrm{ck}}, \mathrm{MPa}\right)^{*}\end{array}$ & $\begin{array}{l}\text { Flexural strength } \\
\qquad\left(f_{\mathrm{t}}, \mathrm{MPa}\right)^{*}\end{array}$ & $\begin{array}{l}\text { Elastic modulus } \\
(E, \mathrm{MPa})^{*}\end{array}$ & $\begin{array}{l}\text { Shear modulus } \\
(G, \mathrm{MPa})^{*}\end{array}$ \\
\hline Magenes et al. [20] & $3.09-3.76(3.28)$ & $0.112-0.161(0.14)$ & $2200-3000(2550)$ & $739-940(840)$ \\
\hline Krzan $[18]$ & $6.0-7.34$ & 0.03 & $534-1570$ & $214-661$ \\
\hline Rizzano and Sabatino [5] & $2.4-6.2$ & $0.1-0.18$ & $1400-1650$ & $250-660$ \\
\hline Silva et al.^[29] & - & $0.02-0.2$ & $226.5-6708$ & $24.8-546$ \\
\hline Valluzi et al. [30] & $1.45-1.97$ & - & $1450-2390$ & - \\
\hline IS 1905: 1987 [31] & $0.25-8.35$ & $0.05-0.14$ & - & - \\
\hline Eurocode $6[12]$ & - & 0.05 & $1000 * f_{\mathrm{ck}}$ & $0.4 * E$ \\
\hline Building code of Pakistan [32] & - & - & $750 * f_{\mathrm{ck}}$ & $0.4 * E$ \\
\hline Italian code (NTC 08) [33] & $2.6-3.8(3.2)$ & $0.084-0.111(0.10)$ & $1500-1980(1740)$ & $500-660(580)$ \\
\hline
\end{tabular}

${ }^{*}$ Values in braces represent the average/suggested values. ' Used for analysis/compiled in the literature cited.

Pakistan's Building Code [31], given in equation (3). The shear modulus $(G)$ is taken as 0.4 times the modulus of elasticity $(E)$ as given by Eurocode 6 [12]:

$$
E=750 f_{\mathrm{ck}},
$$

where $E$ is the modulus of elasticity and $f_{\mathrm{ck}}$ is the compressive strength of wall.

The density is taken as $2300 \mathrm{~kg} / \mathrm{m}^{3}$, for both the outer walls and inner core. Values of 0.4 and $0.1 \mathrm{MPa}$ as given as Eurocode 6 [12] have been taken for the "Standard Wall" for coefficient of friction and cohesion, respectively. The properties of a standard wall are summarized in Table 2 alongside the range of these parameters used for the analysis.

For the plasticity parameters, the biaxial compressive stress is taken as 1.15 times the uniaxial compressive stress. The residual stress is taken as $20 \%$ of the ultimate value. Other strength-strain parameters are taken from the experiment by Magenes et al. [20].

The "pushover curve" obtained from analysis is idealized into bilinear curve so that the results obtained can be compared. The bilinear idealization for this study is taken as elastic-perfectly plastic idealization. For the idealization of curves, criteria of equal energy input of the idealized and experimental response are assumed. The ultimate displacement is taken as the displacement when the maximum resistance drops to $80 \%$ after the peak. Initial stiffness $\left(K_{\text {ef }}\right)$ is based on two-thirds force criteria as presented in the following equation [18]:

$$
K_{\mathrm{ef}}=\frac{(2 / 3) \cdot F_{\max }}{d_{(2 / 3) \cdot F_{\max }}}
$$

where $d_{(2 / 3) \cdot F_{\max }}$ is the displacement, where the shear force reaches two thirds of the maximum shear force.

3.1. Effects of Parameters. The modelling is done in ANSYS by varying different parameters as shown in Table 2. All other parameters are kept as that of a "Standard Wall". A total of 302 models have been prepared and analysed, and the obtained pushover curve is bilinearized to get the yield point and ultimate point.

3.1.1. Height. For a varying height of 0.25 meters to 3.00 meters in increments of 0.25 meters, the ultimate force, yield
TABLE 2: Parameter of "Standard Wall" and range used for analysis.

\begin{tabular}{lcc}
\hline Properties & $\begin{array}{c}\text { Standard } \\
\text { wall }\end{array}$ & $\begin{array}{c}\text { Range for } \\
\text { analysis }\end{array}$ \\
\hline Height $(\mathrm{m})$ & 1.50 & $0.25-3.00$ \\
Length $(\mathrm{m})$ & 1.00 & $0.25-3.50$ \\
Thickness $(\mathrm{m})$ & 0.40 & $0.20-0.75$ \\
Inner: outer thickness ratio & 0.67 & $0.01-1.00$ \\
Compressive strength of outer wall & 3.20 & $1.00-10.00$ \\
(MPa) & 0.50 & $0.10-1.00$ \\
Inner: outer strength ratio & 7.50 & $5.00-50.00$ \\
Precompression $\left(\% f_{\mathrm{ck}}\right)$ & 0.40 & $0.01-0.75$ \\
Coefficient of friction & 0.10 & $0.00-1.00$ \\
Cohesion $(\mathrm{MPa})$ & & \\
\hline
\end{tabular}

displacement, and ultimate displacement are presented in Figures 5-7, respectively. It is seen that the ultimate resistance of a wall decreases with the increase in height while the yield displacement and ultimate displacement increase with increase in height.

3.1.2. Length. As with height, the length has been varied from 0.25 meters to 3.00 meters in increments of 0.25 meters, and the results are presented in Figures 8-10, respectively. It is seen that with the increase in length, the ultimate capacity of the wall increases whereas the yield displacement and ultimate displacement decrease as expected. However, it can be seen that the yield displacement decreases rapidly up to 1 meter and then remains almost constant after 1.5 meter of the length. As for the ultimate displacement, peaks are seen at the length of 0.75 meter.

3.1.3. Thickness. The effect of varying thickness on ultimate force for different coefficient of frictions is shown in Figure 11. It is clearly seen that the ultimate force increases with increase in thickness of the wall. However, a clear correlation of thickness with displacement parameters could not be established and are not presented.

3.1.4. Inner to Outer Thickness Ratio. The ultimate force, yield displacement, and ultimate displacement with change in thickness ratio of the wall are analysed. However, the 


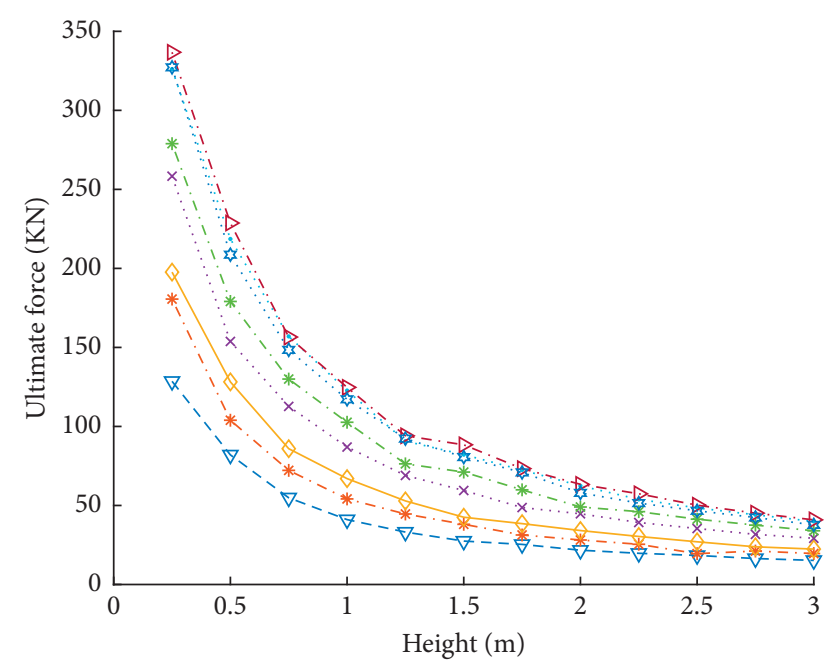

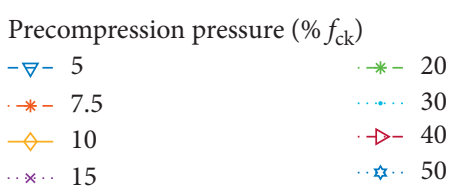

FIgURE 5: Ultimate force vs height plot for different precompression ratios.

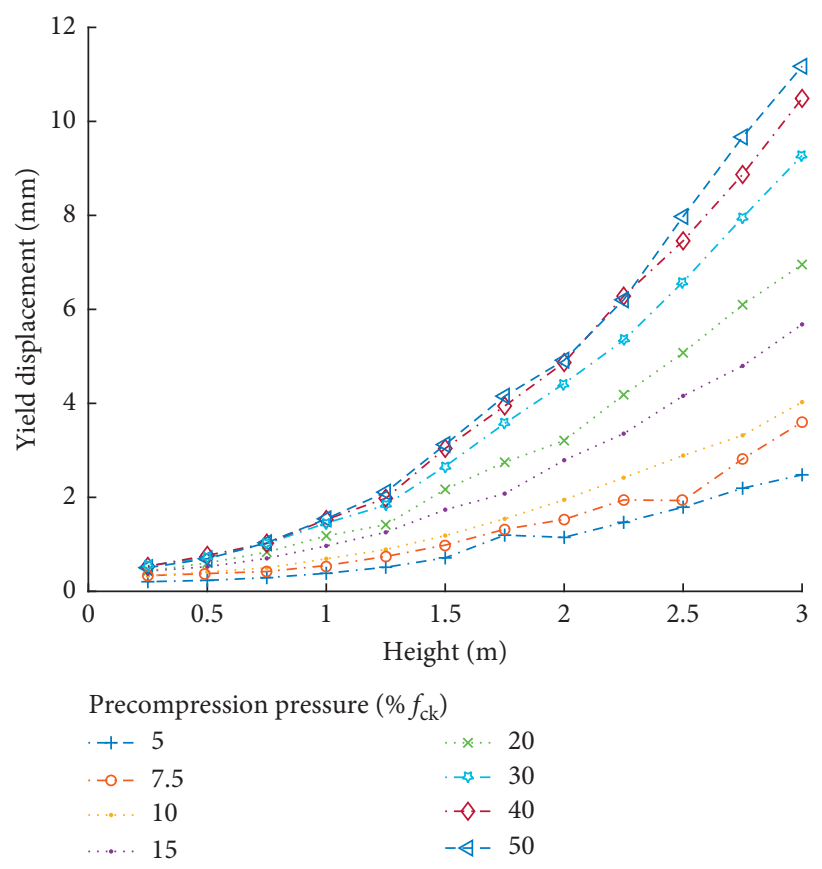

Figure 6: Yield displacement vs height plot for different precompression ratios.

trends of the capacity and displacement parameters with the inner to outer thickness ratio are not observed.

3.1.5. Precompression Pressure. The precompression pressure has been varied from $5 \%$ to $50 \%$ of the compressive

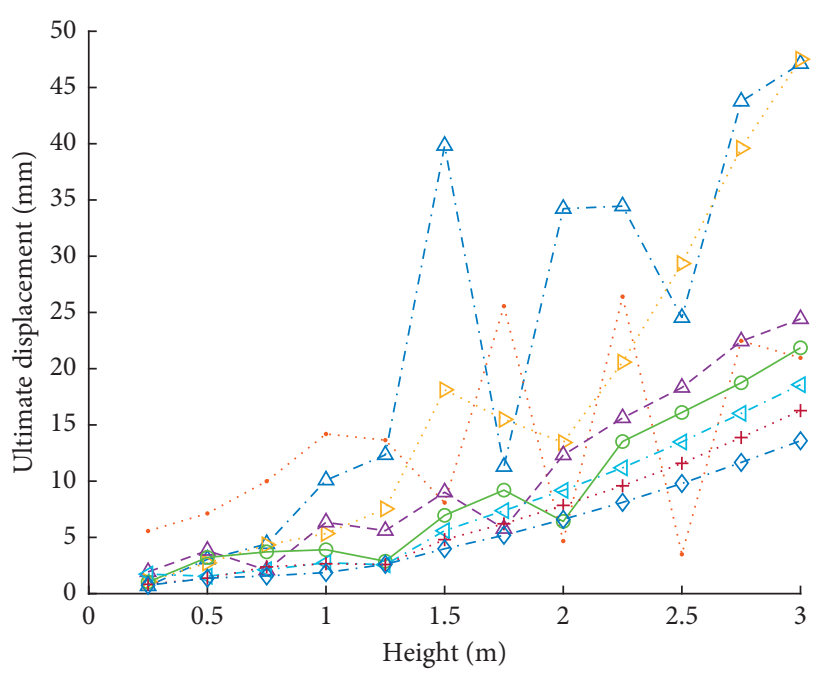

Precompression pressure $\left(\% f_{\mathrm{ck}}\right)$

$\begin{array}{ll}-\Delta-5 & -20 \\ \cdots \cdots 7.5 & \triangleleft-30 \\ -\triangle 10 & \cdots+\cdots 40 \\ -\Delta-15 & -\diamond-50\end{array}$

FIgURE 7: Ultimate displacement vs height plot for different precompression ratios.

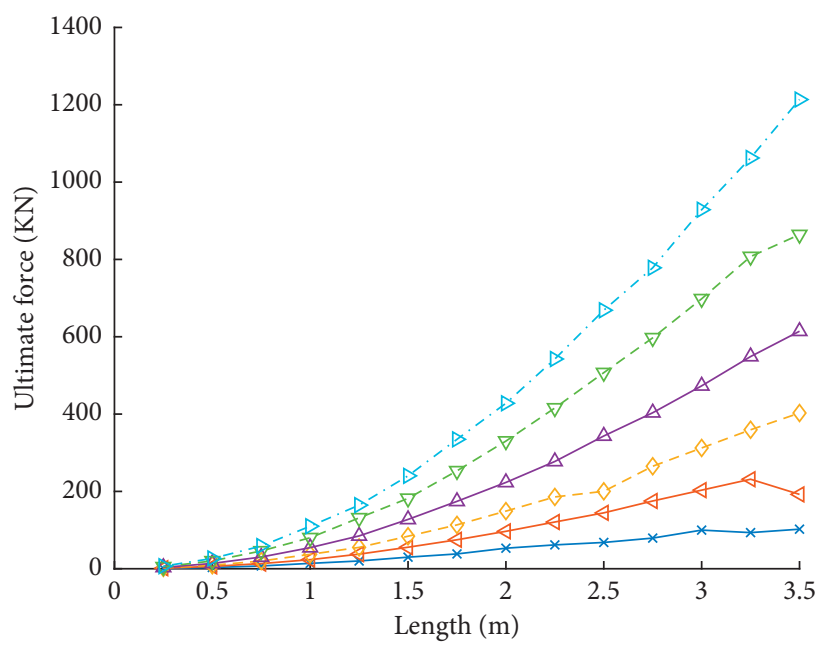

$$
\begin{array}{ll}
\text { Compressive strength outer wall (MPa) } \\
-\leftarrow 1 & -5 \\
-42 & -\nabla-7.5 \\
-\diamond-3.2 & \rightarrow-10
\end{array}
$$

FIGURE 8: Ultimate force vs length for varying compressive strengths.

strength of the outer wall. The effect of precompression pressure on the ultimate force, yield displacement, and ultimate displacement is shown in Figures 12-14, respectively. From the figures, it is clear that, with the increase in the precompression pressure on the wall, the lateral capacity of the wall increases. The yield displacement also increases with the increase in pressure at the top whereas the ultimate displacement decreases. 


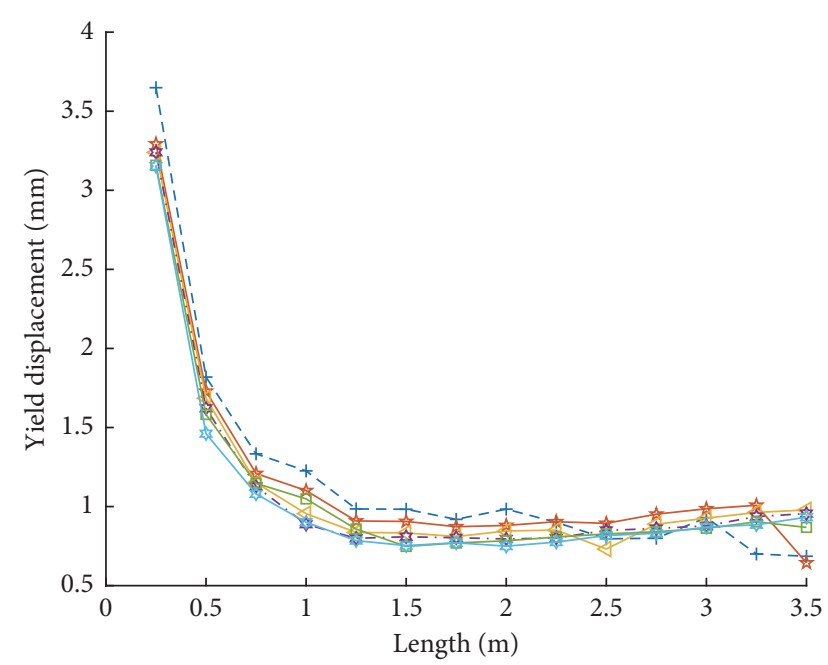

Compressive strength outer wall (MPa)

$$
\begin{aligned}
& -+-1 \text { - } 5 \\
& \pitchfork 2 \quad-7.5 \\
& \rightarrow 3.2+\frac{1}{4} 10
\end{aligned}
$$

FIGURE 9: Yield displacement vs length for varying compressive strengths.

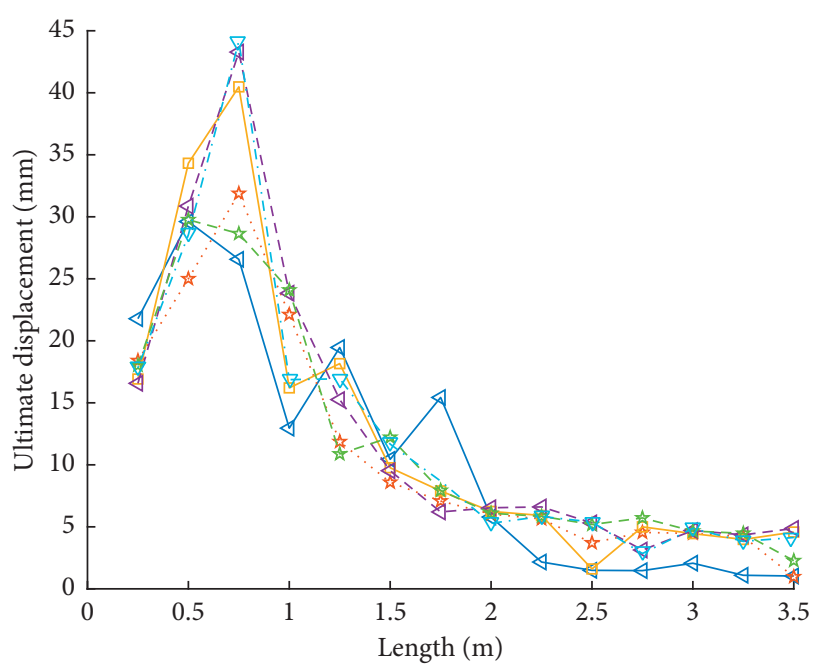

$$
\begin{array}{ll}
\text { Compressive strength outer wall }(\mathrm{MPa}) \\
\varangle 1 & -\varangle-5 \\
\varangle-1 & -\downarrow-7.5 \\
-\square-2 & -\nabla-10
\end{array}
$$

Figure 10: Ultimate displacement vs length for varying compressive strengths.

3.1.6. Compressive Strength. The compressive strength of the outer wall is varied from $1 \mathrm{MPa}$ to $10 \mathrm{MPa}$, and the results are plotted in Figures 15 and 16. As expected, the ultimate lateral resistance of the wall increases with increase in the compressive strength. However, the effect of the increase on the yield displacement and ultimate displacement seems to be unaffected.

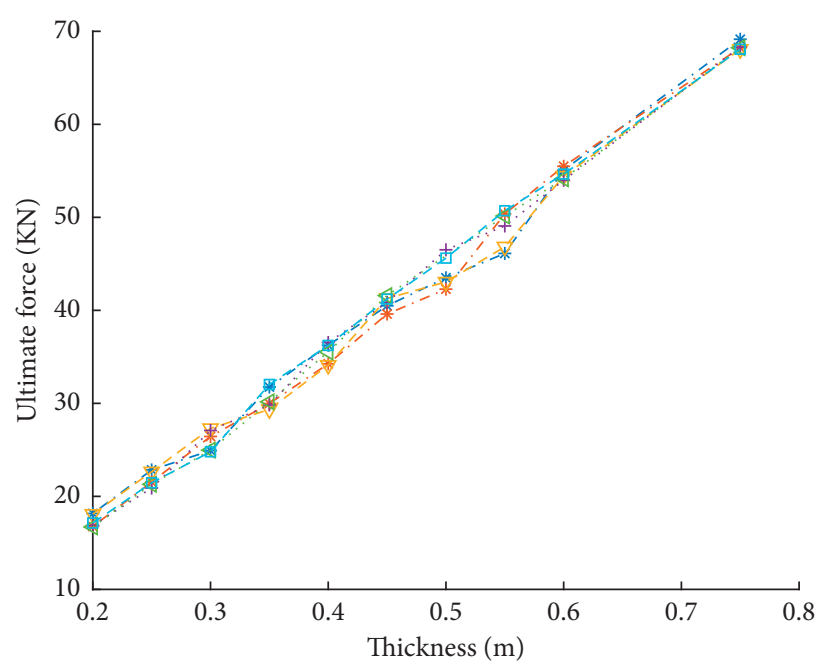

Coefficient of friction

$$
\begin{aligned}
& \begin{array}{lll}
*-0.01 & \cdot+\cdot \cdot 0.4
\end{array}
\end{aligned}
$$

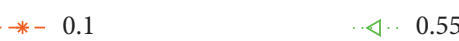

$$
\begin{aligned}
& -\nabla-0.25 \quad-\text { - }-0.75
\end{aligned}
$$

FIGURE 11: Ultimate force vs thickness for varying coefficients of friction.

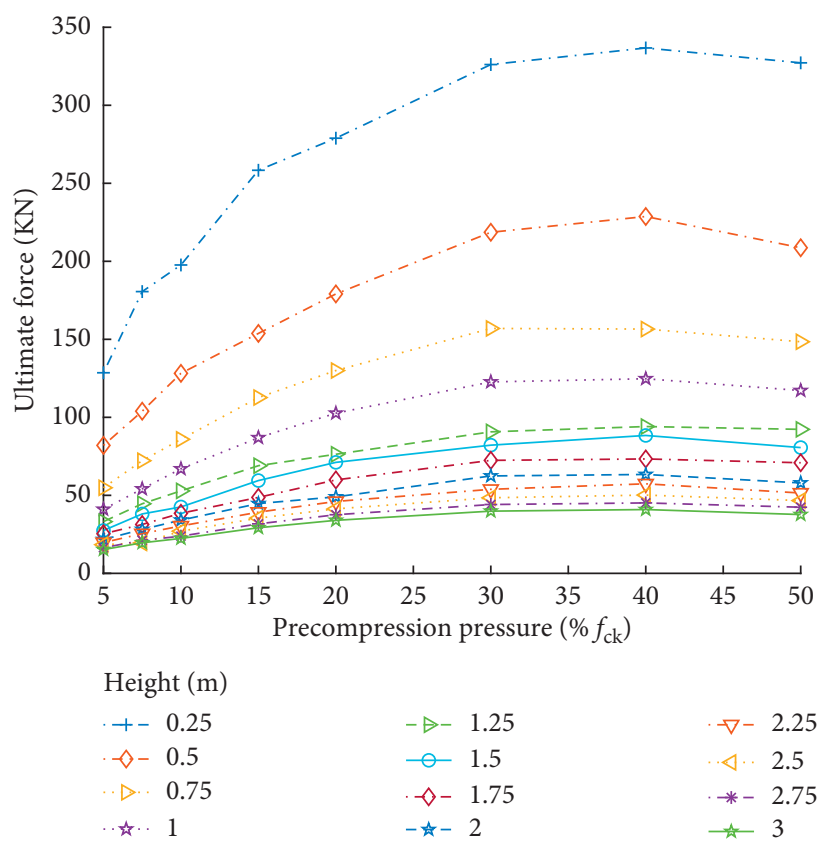

FIGURE 12: Ultimate force vs precompression ratio for different heights.

3.1.7. Strength Ratio of Inner to Outer Wall. The capacity parameters of a multi-leaf stone masonry wall with changing strength ratios for different inner to outer thickness ratios have been analysed. With the thickness ratio, the change in strength ratio does not show a clear correlation with the capacity parameters of the wall. 


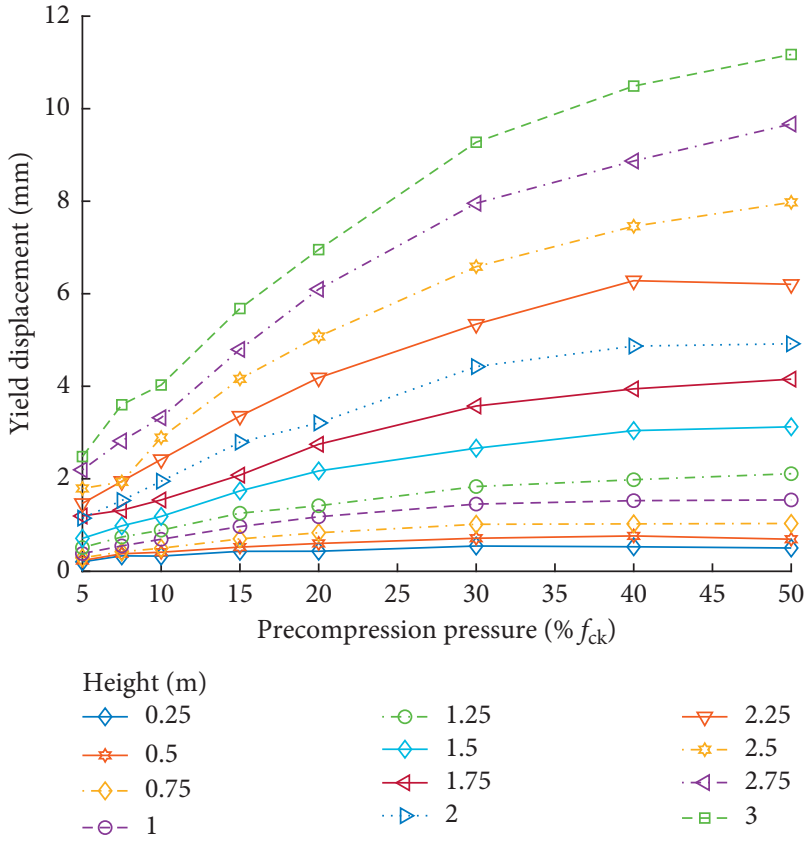

Figure 13: Yield displacement vs precompression ratio for different heights.

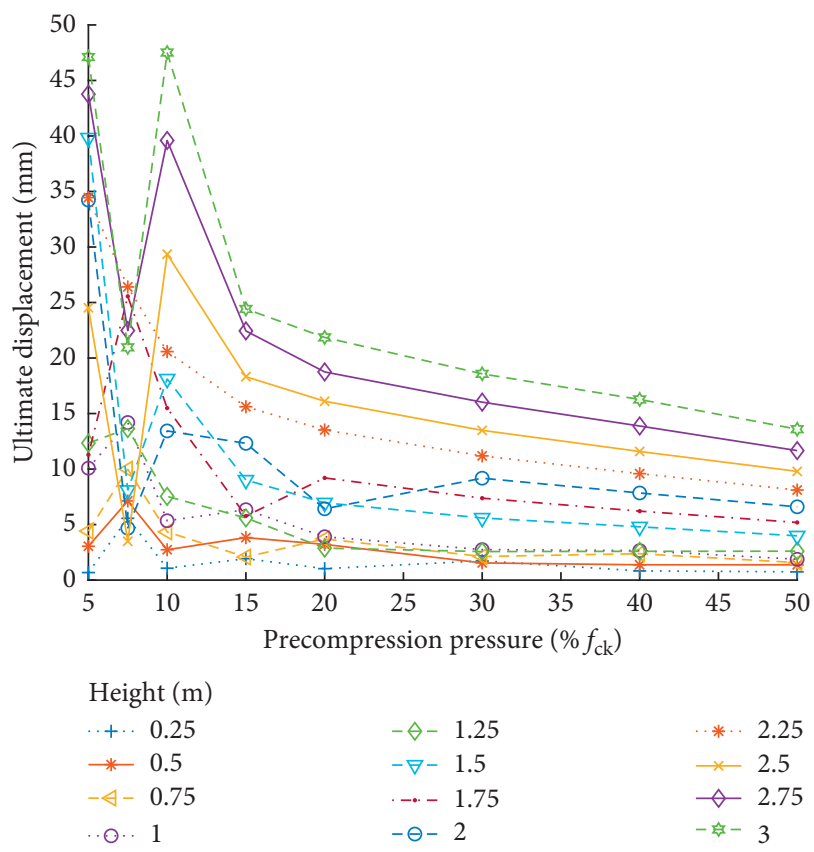

FIGURE 14: Ultimate displacement vs precompression ratio for different heights.

3.1.8. Coefficient of Friction and Adhesion between the Leaves. The coefficient of friction between the layers is varied from 0.01 to 0.75 , while the adhesion is taken from $0.00 \mathrm{MPa}$ to $1.00 \mathrm{MPa}$. The ultimate force for varying the coefficient of friction grouped by different thicknesses of wall is

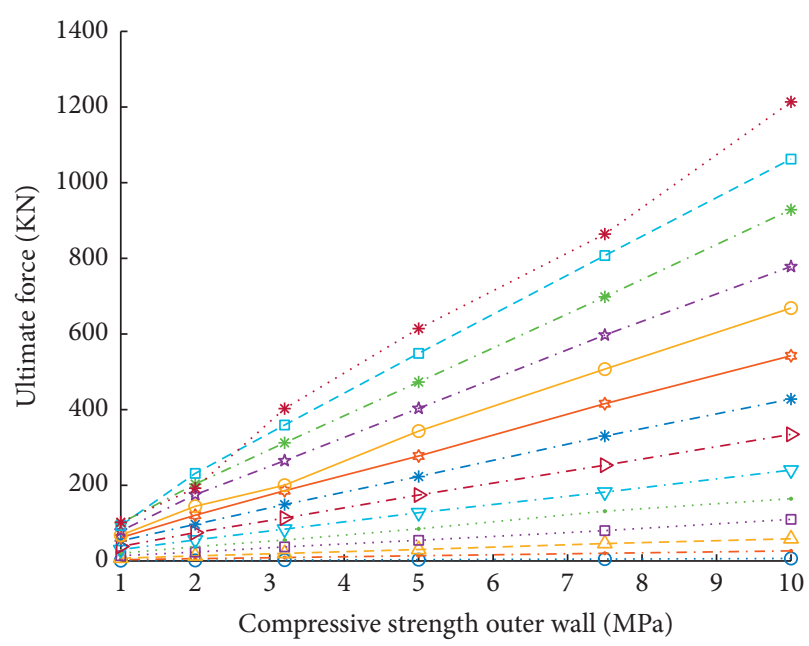

Length (m)

\begin{tabular}{|c|c|c|}
\hline$\cdot 0 . .0 .25$ & $\nabla-1.5$ & $\Rightarrow-2.75$ \\
\hline-0.5 & $\rightarrow-1.75$ & $*-3$ \\
\hline$-\Delta-0.75$ & $*-2$ & -曰- 3.25 \\
\hline a.. 1 & $\leadsto 2.25$ & $\cdots * . \quad 3.5$ \\
\hline $\begin{array}{lll}\ldots . .2 & 1.25\end{array}$ & -2.5 & \\
\hline
\end{tabular}

FIGURE 15: Ultimate force vs compressive strength of outer wall for different lengths.

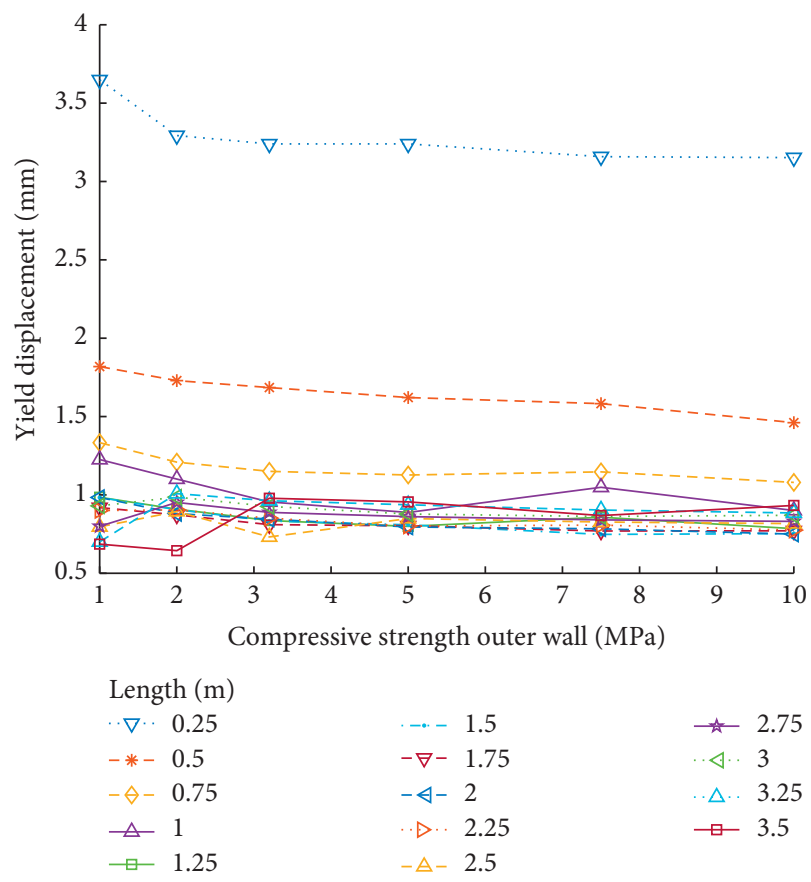

FIGURE 16: Yield displacement vs compressive strength of outer wall for different lengths.

presented in Figure 17, while the ultimate force, yield displacement, and ultimate displacement for different values of cohesion grouped by precompression pressure are presented in Figures 18-20, respectively. Both the 

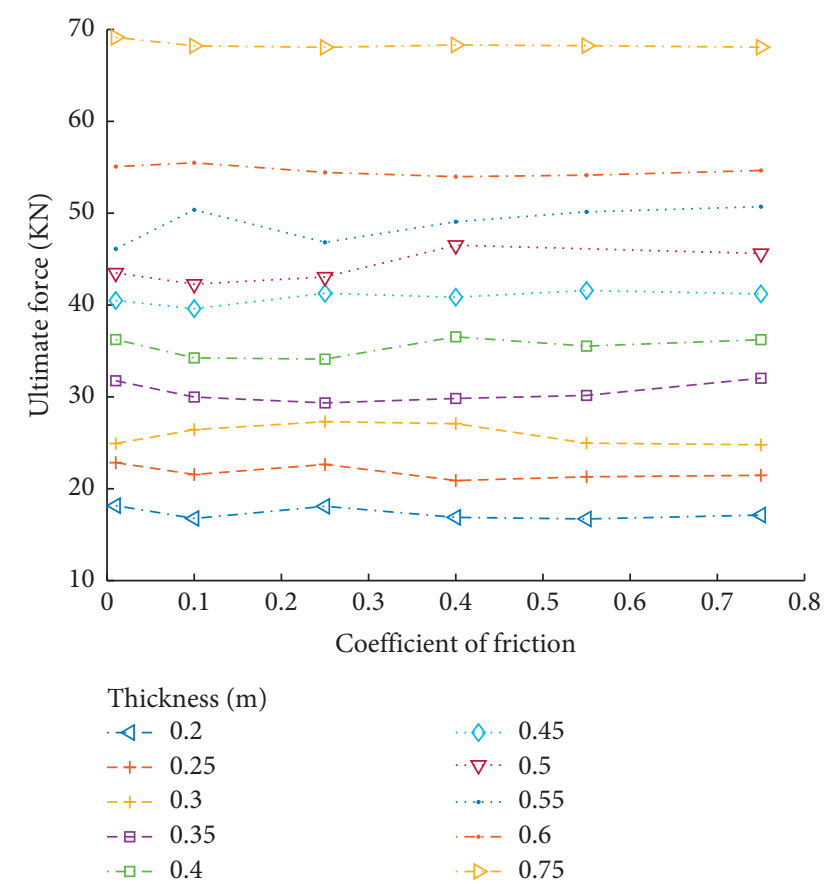

FIGURE 17: Ultimate force vs coefficient of friction for varying thicknesses.

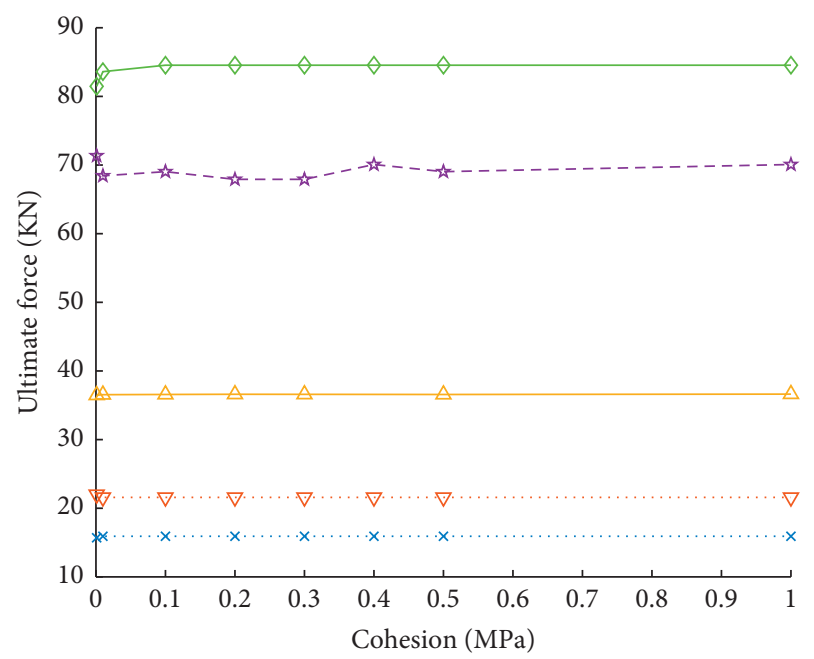

$$
\begin{aligned}
& \text { Precompression pressure }\left(\% f_{\mathrm{ck}}\right) \\
& \times 0.5 \quad-\frac{1}{2}-20 \\
& \nabla \cdot 3 \quad \diamond 50 \\
& \triangle 7.5
\end{aligned}
$$

FIGURE 18: Ultimate force vs cohesion for varying precompression pressures.

coefficient of friction and cohesion are almost constant for the ultimate force. The plots of cohesion with the displacement parameters show that displacement parameters are constant with change in cohesion. However, there seems to be no clear relation between the coefficient of friction and displacement parameters and hence are not presented here.

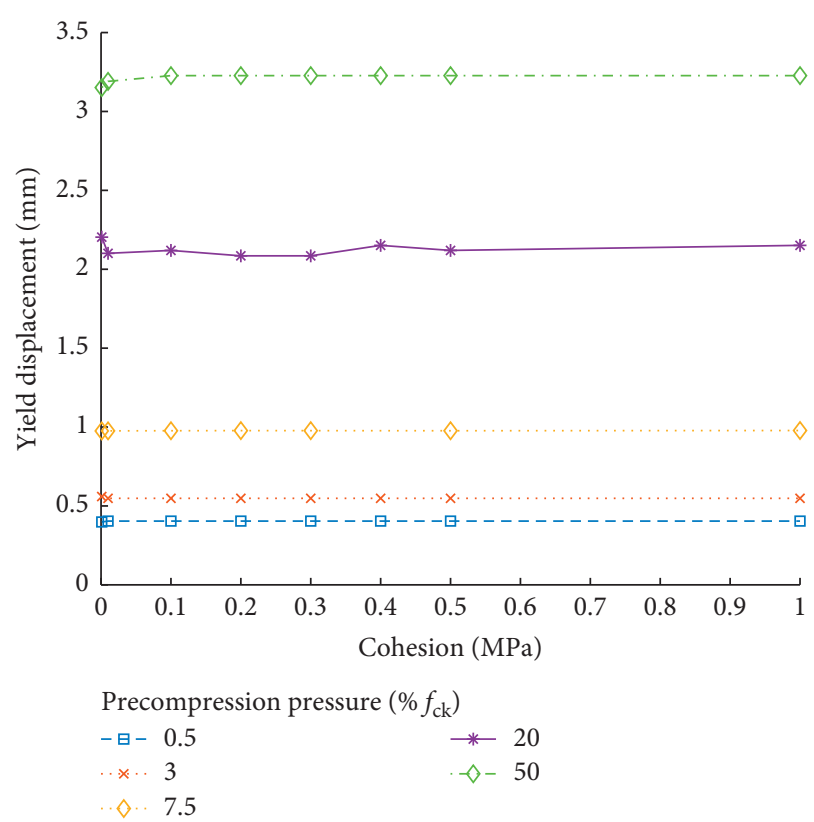

FIgURE 19: Yield displacement vs cohesion for varying precompression pressures.

3.2. Model of Capacity Parameters. Section 3.1 presents the relationship of individual physical and mechanical parameters with capacity and displacement parameters. As observed, once the relationship of individual parameters with the capacity of the multi-leaf stone masonry wall is examined, a model is prepared to obtain the capacity of a wall from its physical and strength parameters are defined. In order to do so, nonlinear regression analysis has been conducted in Statistical Package for the Social Sciences (IBM SPSS Statistics 25) software package to obtain the model.

Nonlinear regression analysis has been conducted for the pushover curve parameters, namely, ultimate force $\left(F_{y}\right)$, yield displacement $\left(d_{y}\right)$, and ultimate displacement $\left(d_{u}\right)$. Curve fitting (linear, quadratic, power, exponential, and logarithmic) have been carried on each parameter, and the best curve fitting were combined so that the fitted curve represents the trend of the physical and strength parameter with respect to a capacity parameter as accurately as possible. The choice whether to include a parameter in the nonlinear regression model was determined based on its contribution on enhancing the coefficient of regression of the model proposed. To determine the best regression model, three statistical parameters were looked upon: adjusted $R$-squared, standard error of parameter estimates, and average absolute error of the predicted and actual value. The best regression model is selected for each of the capacity parameters.

Finally, the equations proposed for the ultimate force $\left(F_{u}\right)$ expressed in $\mathrm{KN}$, yield displacement $\left(d_{y}\right)$, and ultimate displacement $\left(d_{u}\right)$ expressed in millimetres are given in equations (5)-(7), respectively. Table 3 presents the coefficients for equations (5)-(7) and the standard error associated with each constant found from the statistical analysis. The model provided in equations (5)-(7)has an average 


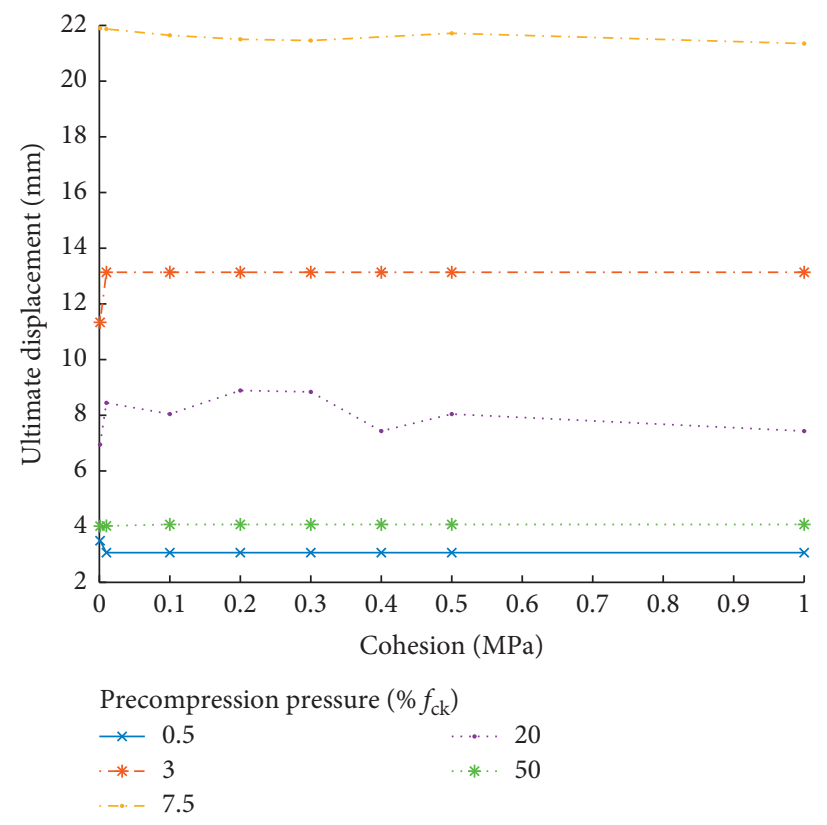

FIGURE 20: Ultimate displacement vs cohesion for varying precompression pressures.

TABLE 3: Coefficient estimates for regression with standard error.

\begin{tabular}{|c|c|c|c|c|c|c|}
\hline \multirow{2}{*}{ Coefficient } & \multicolumn{2}{|c|}{ Ultimate force $\left(F_{u}\right)$} & \multicolumn{2}{|c|}{ Yield displacement $\left(d_{y}\right)$} & \multicolumn{2}{|c|}{ Ultimate displacement $\left(d_{u}\right)$} \\
\hline & Estimate & Std. error & Estimate & Std. error & Estimate & Std. error \\
\hline$c 1$ & 3.721 & 0.281 & 0.083 & 0.003 & 5.165 & 1.022 \\
\hline$c 2$ & 0.269 & 0.020 & 0.611 & 0.010 & 0.146 & 0.041 \\
\hline$c 3$ & -0.691 & 0.021 & 0.871 & 0.011 & -81.367 & 6.237 \\
\hline$c 4$ & 0.775 & 0.011 & -0.743 & 0.026 & - & - \\
\hline$c 5$ & -0.092 & 0.004 & - & - & - & - \\
\hline
\end{tabular}

deviation of $19 \%, 19 \%$, and $29 \%$, respectively from the values obtained from analysis:

$$
\begin{aligned}
& F_{u}=c 1 \cdot p^{c 2} \cdot h^{c 3} \cdot e^{c 4 \cdot l} \cdot c^{c 5} \cdot f_{c k} \cdot t, \\
& d_{y}=c 1 \cdot p^{c 2} \cdot e^{h \cdot c 3} \cdot l^{c 4}, \\
& d_{u}=c 1 x 10^{-3} \cdot\left(f_{c k}\right)^{c 2} \cdot(p+c 3)^{2} \cdot e^{-l} \cdot h,
\end{aligned}
$$

where $c 1, c 2, c 3, c 4$, and $c 5$ are the estimates of constants defined in $p$ which is the precompression pressure in percent of compressive strength, $h, l$, and $t$ are the height, length, and thickness of the wall in meters, $c$ is the cohesion between layers in $\mathrm{MPa} f_{\mathrm{ck}}$ which is the compressive strength of the outer wall in MPa.

\section{Conclusions}

The paper presents the nonlinear modelling approaches in stone masonry and multi-leaf stone masonry. Considering the assumptions and simplifications have been made in the process of obtaining the mathematical model of capacity assessment of multi-leaf stone masonry wall, some conclusions may be drawn, presented in bullets as follows: (i) This paper presents with finite element modelling technique for multi-leaf stone masonry structure. Verification of the results from this novel approach of finite element analysis using ANSYS with experimental result shows that it is possible to model multi-leaf stone masonry walls with reasonable accuracy. This method of modelling can be used in modelling similar materials.

(ii) The novel contribution of the study is that it provides a set of equations to predict the capacity parameters, namely, ultimate force, yield displacement, and ultimate displacement of a multi-leaf stone masonry wall. This can be a handy tool for engineers and alike to quickly estimate the capacity parameters of multi-leaf stone masonry walls and make informed decision. Though this approach cannot replace more sophisticated modelling approaches, this can act as a handy and simplified tool.

(iii) One of the applications of the set of equations presented is that they can be further used to perform a simplified capacity assessment of multi-leaf stone masonry structures using equivalent frame method. This can provide designers and engineers with a 
simplified way to carry out the capacity assessment of multi-leaf stone masonry structures.

\section{Data Availability}

The MAPDL scripts and the results obtained from the finite element analysis are available on the Mendeley Repository at https://dx.doi.org/10.17632/czs9vvy8h4.2. Data from sources other than those generated by the authors used have been properly cited as references text.

\section{Conflicts of Interest}

The authors declare that they have no conflicts of interest.

\section{References}

[1] M. Tomazevic, The Computer Program POR, Report ZRMK, Ljubljana, Slovenian, 1978.

[2] G. Magenes and G. M. Calvi, "In-plane seismic response of brick masonry walls," Earthquake Engineering \& Structural Dynamics, vol. 26, no. 11, pp. 1091-1112, 1997.

[3] Y. Belmouden and P. Lestuzzi, "An equivalent frame model for seismic analysis of masonry and reinforced concrete buildings," Construction and Building Materials, vol. 23, no. 1, pp. 40-53, 2007.

[4] L. Pasticier, C. Amadio, and M. Fragiacomo, "Non-linear seismic analysis and vulnerability evaluation of a masonry building by means of the SAP2000 v.10 code," Earthquake Engineering \& Structural Dynamics, vol. 37, no. 3, pp. 467-485, 2008.

[5] G. Rizzano and R. Sabatino, "An equivalent frame model for the seismic analysis of masnory structures," in Proceedings of the 8th Congresso de Sismologia e Engenharia Sismica, Aveiro, Portugal, October 2010.

[6] S. Petrovcic and V. Kilar, "Sesimic failure mode interaction for the equivalent frame modeling of unreinforced masonry structures," Engineering Structures, vol. 54, pp. 9-22, 2013.

[7] S. Lagomarsino, A. Penna, A. Galasco, and S. Cattari, "TREMURI program: an equivalent frame model for the nonlinear seismic analysis of masonry buildings," Engineering Structures, vol. 56, pp. 1787-1799, 2013.

[8] N. Zheng, J. Zhou, Y. Yin, J. Han, and S. Ji, "Non-linear time history response analysis of low masonry structure with tiecolumns," in Proceedings of the World Conferences on Earthquake Engineering, Lisbon, Portugal, September 2012.

[9] A. L. Abbas and M. H. Saeed, "Representation of the masonry walls techniques by using FEM," Australian Journal of Basic and Applied Sciences, vol. 11, no. 13, pp. 39-48, 2017.

[10] A. Akhaveissy, "The DSC model for the nonlinear analysis of in-plane loaded masonry structures," The Open Civil Engineering Journal, vol. 6, no. 1, pp. 200-214, 2012.

[11] J. A. C. Barraza, Numerical Model for Nonlinear Analysis of Masonry Walls, Ph.D. dissertation, Rheinisch-Westfälische Technische Hochschule Aachen, Aachen, Germany, 2012.

[12] Eurocode 6 (EN 1996), Design of Masonry Structures, European Committee for Standardization, Brussels, Belgium, 2005.

[13] L. Binda, G. Cardani, and A. Saisi, "A classification of structures and masonries for the adequate choice of repair," in Proceedings of the International RILEM Workshop on Repair Mortars for Historic Masonry, Delft, Netherlands, January 2015.

[14] M. A. Ramalho, A. Taliercio, A. Anzani, L. Binda, and E. Papa, "A numerical model for the description of the nonlinear behaviour of multi-leaf masonry walls," Advances in Engineering Software, vol. 39, no. 4, pp. 249-257, 2008.

[15] B. Al-Gohi, C. Demir, A. Ilki, M. Baluch, M. Rahman, and A. Al-Gadhib, "Sesimic vulnerability of multi-leaf heritage masonry walls using elasto-plastic damage model," in Proceedings of the 3rd International Workshop: Role of Research Infrastructures in Seismic Rehabilitation, Istanbul, Turkey, February 2012.

[16] G. Castellazzi, D. Ciancio, and F. Ubertini, "A simplified micro-modeling approach for historical stone masonry walls," Key Engineering Materials, vol. 624, pp. 74-79, 2014.

[17] M. Betti, L. Galano, and A. Vignoli, "Time-history seismic analysis of masonry buildings: a comparison between two non-linear modelling approaches," Buildings, vol. 5, no. 2, pp. 597-621, 2015.

[18] M. Kržan, "Performance based experimental and numerical assessment of multi-leaf stone masonry walls," Doctoral dissertation, Univerza v Ljubljani, Ljubljana, Slovenia, 2015.

[19] S. Chiostrini, L. Galano, and A. Vignoli, "On the determination of strength of ancient masonry walls via experimental tests," in Proceedings of the World Conferences on Earthquake Engineering, Auckland, New Zealand, February 2000.

[20] G. Magenes, A. Penna, A. Galasco, and M. Rota, "Experimental Characterisation of stone masonry mechanical properties," in Proceedings of the 8th International Masonry Conference, Dresden, Germany, July 2010.

[21] J. Milosevic, A. S. Gago, M. Lopes, and R. Bento, "Experimental tests on rubble masonry specimens- diagonal compression, triplet and compression tests," in Proceedings of the World Conferences on Earthquake Engineering, Lisboa, Portugal, September 2012.

[22] A. Anzani, L. Binda, A. Fontana, and J. P. Henriques, "An experimental investigation on multiple-leaf stone masonry," in Proceedings of the 13th International Brick and Block Masonry Conference, Amsterdam, Netherlands, July 2001.

[23] N. Mazzon, M. R. Valluzzi, T. Aoki et al., "Shaking table tests on two multi-leaf stone masonry buildings," in Proceedings of the 11th Canadian Masonry Symposium, Toronto, Canada, June 2009.

[24] G. Magenes, A. Penna, and A. Galasco, "A full-scale shaking table test on a two-storey stone masonry building," in Proceedings of the 14th European conference on earthquake engineering, Ohrid, Macedonia, September 2010.

[25] Q. Ali, A. N. Khan, M. Ashraf et al., "Seismic performance of stone masonry buildings used in the himalayan belt," Earthquake Spectra, vol. 29, no. 4, pp. 1159-1181, 2013.

[26] ANSYS Inc., Mechanical APDL $19.2 \mathrm{Help,} \mathrm{ANSYS} \mathrm{Inc.,}$ Canonsburg, PA, USA, 2019.

[27] A. Aldemir, "A simple seismic performance assessment technique for unreinforced masonry structures," M.S. dissertation, Middle East Technical University, Ankara, Turkey, 2010.

[28] L. Binda, A. Fontana, and L. Anti, "Load transfer in multiple leaf masonry walls," in Proceedings of the International Workshop Effectiveness of injection techniques for retrofitting of stone and brick masonry walls in seismic areas, Milan, Italy, March 1992.

[29] B. Silva, M. D. Benetta, F. d. Porto, and C. Modena, "Experimental assessment of in-plane behaviour of three-leaf stone masonry walls," Construction and Building Materials, vol. 53, pp. 149-161, 2014.

[30] M. Valluzi, F. D. Porto, and C. Modena, "Behavior and modeling of strengthened three-leaf stone masonry walls," Materials and Structures, vol. 37, no. 3, pp. 184-192, 2004. 
[31] IS 1905, Code of Practice for Structural Use of Unreinfroced Masonry, Bureau of Indian Standards, New Delhi, India, 1987.

[32] BCP, Building Code of Pakistan, Ministry of Housing and Works, Government of Pakistan, Islamabad, Pakistan, 2007.

[33] NTC 08, Norme Tecniche per le Costrunzioni, Ministero delle Infrastructture e dei Transporti, Rome, Italy, 2008.

[34] TEC 2007, Specifications for Structures to Be Built in Disaster Areas, Turkish Ministry of Public Works and Settlement, Ankara, Turkey, 2007. 